\title{
Correlation between Uncontrolled Blood Glucose and Oxidative Stress with Urinary Nephrin Level in Type 2 Diabetes Mellitus
}

\author{
Dinda Aprilia ${ }^{1}$, Sri Angraeni ${ }^{2}$, Eva Decroli ${ }^{3}$, Asman Manaf $^{4}$, Syafril Syahbuddin $^{5}$, \\ \{dinda_oink@yahoo.com ${ }^{1}$ \}
}

Division of Endocrinology and Metabolism, Department of Internal Medicine, Faculty of Medicine, Universitas Andalas, Padang, West Sumatera

\begin{abstract}
Diabetes mellitus (DM) is one of the world's health problem with increasing prevalence and important medical and social impacts. Diabetes mellitus causes micro and macrovascular complications depending on the presence of blood glucose level disorder. Impaired glucose levels have two components, chronic hyperglycemia and acute fluctuations of blood glucose levels from peak to nadir. These two components cause DM with two main mechanisms, protein glycation, and oxidative stress. Glycated albumin describes uncontrolled medium range glucose level while malondialdehyde reflects oxidative stress. Nephrin is one of the damage markers of podocyte that represents diabetic kidney disease. To find out the correlation between uncontrolled blood glucose with urinary nephrin level in a patient with type 2 diabetes mellitus. This is an observational study with the cross-sectional method. Subjects are 30 types $2 \mathrm{DM}$ patients. Patients serum glycated albumin (GA) are measured, along with serum malondialdehyde (MDA) and urinary nephrin. Among 30 types $2 \mathrm{DM}$ patients, there is a significant increase in GA and MDA level. Mean serum GA level is $20,87 \%(5,91) \%$, serum MDA level is $9,24(5,59-$ $13,59)$ and urinary nephrin is $369,25(6-3952) \mathrm{ng} / \mathrm{ml}$. There is a moderate correlation between serum GA with urinary nephrin $(p=0,027)$ and moderate correlation between serum MDA and urinary nephrin $(\mathrm{p}=0,003)$. There is a correlation between uncontrolled blood glucose with urinary nephrin level in type 2 diabetes mellitus.
\end{abstract}

Keywords: Glycated Albumin, Serum Malondialdehyde, Type 2 DM, Uncontrolled Blood Glucose, Urinary Nephrin.

\section{Introduction}

Diabetes mellitus (DM) is one of the world's health problem with increasing prevalence and important medical and social impact. According to the International Diabetes Federation (2013), 382 million people across the world had DM in 2013. The global prevalence of diabetes in 2035 is predicted to increase to 592 million people. In 2013, Southeast Asia held 72 million adults with diabetes and is estimated to increase to 123 million people in 2035. A significant increase in the DM prevalence occurs in Southeast Asia including Indonesia. In 2030 DM sufferers is estimated to be 21,3 million people [1],[2].

Diabetes mellitus can cause microvascular complication, including diabetic kidney disease (PGD) [3],[4]. Based on the American Diabetes Association (ADA), PGD occurs in 20-40\% DM patient and becomes the main cause of end-stage renal disease [5],[6]. 
Protein in the human body can be glycated. Glycation of various proteins increases in diabetic patients, as of these glycated proteins can be utilized to evaluate diabetes controlling. Of all glycated proteins, HbAlc is the gold standard for glycaemic control. In the last few years, glycated albumin (GA) becomes an index of glycation for medium range uncontrolled blood glucose because of the short albumin half-life compared to erythrocyte [7],[8].

Oxidative stress is caused by unbalanced production of oxidant or ROS and detoxification capacity to repair cell damage. There is a direct relationship between kidney damage severity with oxidative stress level in diabetic kidney disease. Several markers have been used to measure oxidative stress in diabetic patients. One of the markers is malondialdehyde (MDA) [9],[10]

In DM patient, a further pathologic kidney change occurs. Three components become the glomerular filtration barrier, which is the podocyte, capillary endothelial cell, and glomerular basal membrane. Certain proteins can reflect the condition of podocyte and nephrin. In diabetic condition, a downregulation of nephrin take place and acts as an antiapoptotic agent. Released nephrin escapes through the urine and can be detected in patients urine. The loss of nephrin cause flattening foot process of the podocyte and cause the increasing of proteinuria [11],[12].

Many studies show that hyperglycemia plays a role in the pathogenesis of diabetic kidney disease so that a glycaemic control to prevent complication is needed. The protein glycation process causes complication in diabetic patients and the oxidative stress occurred in the patient. Based on those backgrounds, we decided to study the correlation between uncontrolled blood glucose with urinary nephrin level in a patient with diabetes mellitus type 2 [11],[12].

\section{Materials and Methods}

This study is a cross-sectional observational study. Study is conducted in the inpatient room and polyclinic of the Internal Medicine Department RSUP M. Djamil Padang for 6 months. The population of this study is patients with type 2 DM, hospitalized in RSUP M. Djamil Padang or routine polyclinic patients within the age of 18-59 years. Samples are the population that matches the inclusion and exclusion criteria.

A correlation analysis made between serum glycated albumin with urinary nephrin level and the correlation between serum malondialdehyde level and urinary nephrin level. Data is processed with SPSS 21.0, the value of significance is calculated, and is significant if $\mathrm{p}<0,05$.

\section{Results}

Table 1 shows the characteristics of 30 types 2 DM patients. This study consists 11 male patients $(36,67 \%)$ and 19 females $(63,3 \%)$. The mean age of type 2 DM patients is 52,03 years old, the youngest is 37 years old, and the oldest is 59 years old. The most amount of age obtained are 51-59 years old. Patients distribution based on the age groups are, 30-39 years old is 1 patient $(3,33 \%)$, the groups of $40-49$ years old has 8 patients $(26,67 \%)$ and the age $50-59$ years old as much as 21 patients $(70 \%)$. The mean duration of disease suffering is $7,3(5,4)$ years. The mean body mass index is $21,67(3,9) \mathrm{kg} / \mathrm{m}^{2}$. In this study, the average fasting blood glucose is 178,8 $(71,4) \mathrm{mg} / \mathrm{dl}$ and postprandial blood glucose is $219,1(89,7) \mathrm{mg} / \mathrm{dl}$. Mean serum level is 34,7 $(29,4) \mathrm{mg} / \mathrm{dl}$ and creatinine is $1,1(0,5) \mathrm{mg} / \mathrm{dl}$. 
Table 1. Baseline Characteristics

\begin{tabular}{lcc}
\hline Characteristics & $\mathrm{n}(\%)$ & Mean (SD) \\
\hline Gender & $11(36,67)$ & \\
Male & $19(63,33)$ & \\
Female & & \\
Age (year) & $1(3,33)$ & $52,03(5,60)$ \\
$30-39$ & $8(26,67)$ & \\
$40-49$ & $21(70)$ & \\
$50-59$ & & $7,30(5,40)$ \\
Duration of disease suffering (year) & & $21,67(3,90)$ \\
Body Mass Index (kg/m $\left.{ }^{2}\right)$ & $178,80(71,40)$ \\
Fasting Blood Glucose (mg/dl) & & $219,10(89,70)$ \\
Post Prandial Blood Glucose (mg/dl) & $34,70(29,40)$ \\
Ureum (mg/dl) & & $1,10(0,50)$ \\
Creatinine (mg/dl) & & \\
\hline
\end{tabular}

In this study, we obtained the mean level of serum glycated albumin at $20,87(5,91) \%$ (normal value 11-16\%). The result of the Kolmogorov Smirnov normality test shows the serum glycated albumin in this study is normally distributed. After performing one sample t-test, we found the GA level increases significantly with $\mathrm{p}<0,001$.

Table 2. Serum Glycated Albumin in Type 2 DM patients

\begin{tabular}{lcl}
\hline Variable & $\mathrm{n}$ & Mean (SD) \\
\hline Glycated Albumin $(\%)$ & 30 & $20,87(5,91)$ \\
\hline glycated albumin normal value: $11-16 \%$ &
\end{tabular}

In this study, we obtained the level of serum malondialdehyde as much as $9,24 \mathrm{nmol} / \mathrm{ml}$, with the lowest level $5,59 \mathrm{nmol} / \mathrm{ml}$ and the highest is $13,56 \mathrm{nmol} / \mathrm{ml}$. Kolmogorov Smirnov normality test shows the data of serum malondialdehyde level in the study is not normally distributed. Table 3 shows the median level of serum malondialdehyde.

Table 3. Serum Malondialdehyde Level in Type 2 DM patients

\begin{tabular}{llll}
\hline \multicolumn{1}{c}{ Variable } & $\mathrm{n}$ & Median & Minimum - Maximum \\
\hline $\begin{array}{l}\text { Serum Malondialdehyde } \\
(\mathrm{nmol} / \mathrm{ml})\end{array}$ & 30 & 9,24 & $5,59-13,56$ \\
\hline
\end{tabular}

Serum MDA normal value : $0,9-1,59 \mathrm{nmol} / \mathrm{ml}$

In this study, the median level of urinary nephrin is $369,25 \mathrm{ng} / \mathrm{ml}$, with the lowest level is 6 $\mathrm{ng} / \mathrm{ml}$ and the highest is $3952 \mathrm{ng} / \mathrm{ml}$. Kolmogorov Smirnov normality test shows the data of urinary nephrin in the study is not normally distributed. Table 4 provides the median urinary nephrin level.

Tabel 4. Urinary Nephrin Level in Type 2 DM Patients

\begin{tabular}{llll}
\hline Variable & $\mathrm{n}$ & Median & Minimum - Maximum \\
\hline Urinary Nephrin $(\mathrm{ng} / \mathrm{ml})$ & 30 & 369,25 & $6-3952$ \\
\hline Urinary nephrin normal value $:$ not detected & &
\end{tabular}




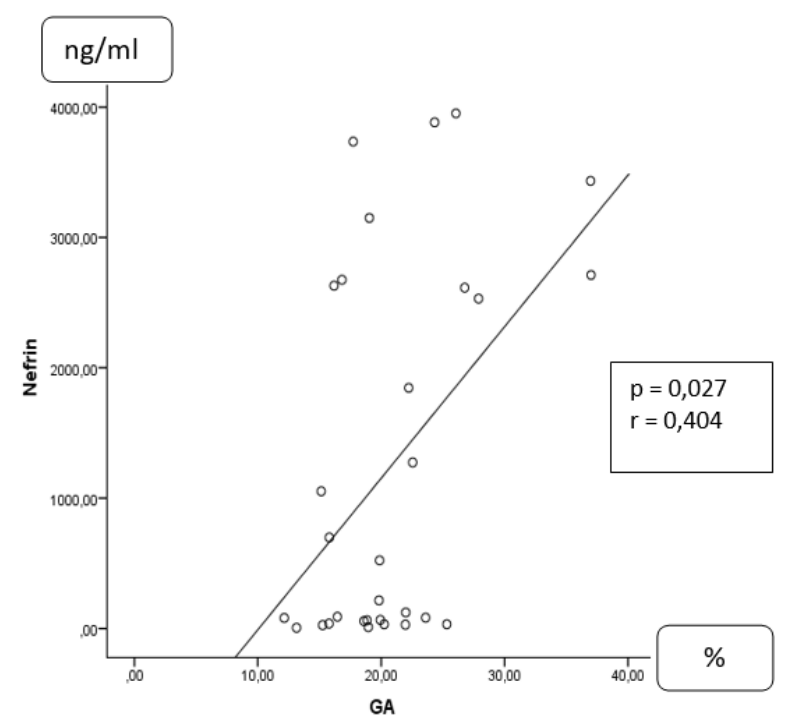

Fig. 1. Graphic of correlation between serum glycated albumin level with urinary nephrin level in the Type 2 DM patients

In figure 1 above, can be seen the correlation between serum glycated albumin level with urinary nephrin level in the Type $2 \mathrm{DM}$ patients. The correlation analysis used is the Spearman correlation test and confidence level obtained is $p<0,05$. The analysis result shows a significant correlation between serum glycated albumin with urinary nephrin level $(p=0,027)$, with positive correlation and the correlation strength is moderate. (Correlation coefficient $r=0,404$ )

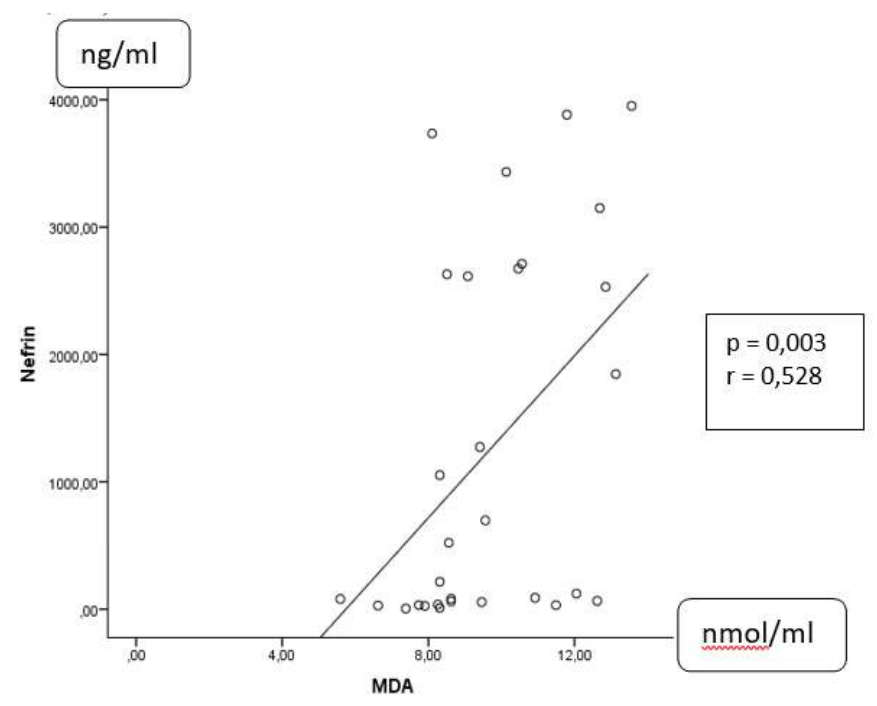

Fig. 2. Correlation graphic between serum malondialdehyde level with urinary nephrin level in type $2 \mathrm{DM}$ patients. 
In the figure above can be seen the correlation between serum malondialdehyde level with urinary nephrin level in type $2 \mathrm{DM}$ patients. Correlation analysis used is the Spearman correlation test and confidence level obtained is $\mathrm{p}<0,05$. The analysis result shows a significant correlation between serum malondialdehyde level with urinary nephrin level $(p=0,003)$ with positive direction and moderate strength of correlation (correlation coefficient $\mathrm{r}=0,528$ ).

\section{Discussion}

\subsection{Baseline Characteristics}

From 30 type 2 DM samples, 19 patients $(63,33 \%)$ were female and 11 are male $(36,67 \%)$. The study by Furusyo et al. (2011) on DM population in Japan found that there are more female patients than the male with a ratio of 70:30. Hilawe et al. (2013) published a meta-analysis of 36 studies and stated that the prevalence of type $2 \mathrm{DM}$ in South Africa is much higher in women compared to men [13],[14].

In this study we found the mean age of type 2 DM patients treated in RSUP Dr. M. Djamil Padang is 52,03 $(5,6)$ years old with the most amount of age groups are 50-59 years old, which is 21 patients (70\%). Lopez et al. (2014) performed a study in New Jersey with 7,239 types 2 DM patients and found the mean age is 59,9 years old. Whereas Solini et al. (2013) reported a multicenter study of type $2 \mathrm{DM}$ in Italia and found an older age range compared to the study, which is 59-73 years old [15],[16].

In this study, the mean disease suffering of the type 2 DM patients is $7,3(5,4)$ years. There is 1 patient who just noticed that he already suffered type $2 \mathrm{DM}$ after 1 month. The study by Petrica et al. (2014) in Greece found that the mean duration of disease suffering in type 2 DM patients is 9 years. Wang et al. (2016) in his study of DM population in China found the mean duration of disease suffering is 9 (3) years. While Solini et al. (2013) found the mean duration of disease suffering in Italia is longer, which is 11 years [16]-[18].

Mean body mass index (BMI) in this study is $21,67(3,9) \mathrm{kg} / \mathrm{m}^{2}$. A similar result is shown by Furusyo et al. (2011) in Japan DM population, who found a mean BMI of $21,6 \mathrm{~kg} / \mathrm{m}^{2}$. Xu Y et al. (2013) studied the type 2 DM population in China and obtained a mean BMI $23,7 \mathrm{~kg} / \mathrm{m}^{2}$, while Flegal KM et al. (2010) found a mean BMI he surveyed as $28,7 \mathrm{~kg} / \mathrm{m}^{2}$ in the population of America [13],[19],[20].

\subsection{Serum Glycated Albumin Level in Type 2 DM Patients}

According to The Committee on Diabetes Mellitus Indices and Japan Society of Clinical Chemistry (JSCC), glycated albumin (GA) is an albumin-containing lysin that bounds to glucose. Diabetes mellitus patients will generate much glycated proteins. These glycated proteins are used to evaluate diabetes controlling, and these protein are also involved in the development and progressivity of long-term diabetic complications. Of all proteins that are glycated, glycated hemoglobin (HbAlc) is used as a gold standard in clinical blood glucose control. In the last few years, GA appear as a possible glycation index that can evaluate a midterm control of diabetes [7],[21].

Average glycated albumin level in this study is $20,87(5,9) \%$ (normal value $11-16 \%$ ). Hsu $\mathrm{P}$ et al. (2015) obtained a lower mean GA level in the type 2 DM population in Taiwan, which is $18,1 \%$. This study was performed to 2.192 type $2 \mathrm{DM}$ patients who received treatment 
previously. Mean age in this study is 60,1 years old. Wang et al. (2016) studied 206 types 2 DM patients in China and found a similar serum GA level with the Taiwan study, which is $17,9(5,9)$ $\%$. Characteristic of the patient in both studies are identical [18],[22].

Glycated albumin describes uncontrolled glucose in type 2 DM patients. This marker has a double role in type 2 DM complications. Besides acting as a glycation marker, GA also acts directly as an agent that cause various complications of diabetes, for instance, nephropathy, atherosclerosis, and diabetic retinopathy [22].

\subsection{Serum Malondialdehyde (MDA) Level in type 2 DM Patient}

Malondialdehyde is one of the markers that represent the condition of oxidative stress. In Type 2 DM patients, hyperglycemia may increase oxidative stress through numerous mechanism, including the induction of ROS. In this study we obtain a median level of malondialdehyde as $9,24 \mathrm{nmol} / \mathrm{ml}$, with the lowest measure of $5,59 \mathrm{nmol} / \mathrm{ml}$ and the highest measure was 13,56 $\mathrm{nmol} / \mathrm{ml}$. MDA level in this study is higher than normal, due to the presence of factors producing oxidative stress to patients in this study, such as fasting blood glucose level, postprandial glucose level, age and duration of disease. Kumawat et al. (2013) reported a significant increase in the malondialdehyde level in type $2 \mathrm{DM}$ patients compared to the control group, with the mean MDA level 7,09 $(1,15) \mathrm{nmol} / \mathrm{ml}$. In this study, we found obesity, uncontrolled blood glucose, and dyslipidemia. BMI increase, uncontrolled blood glucose, and dyslipidemia will increase oxidative stress to patients [23].

Nakhjavani M et al. (2010) compared DM patients and healthy control subjects. It shows a significant increase of MDA level in the DM patients compared to control subjects and the duration of suffering DM is related to lipid peroxidase level. Mean level of MDA is 3,82 $(0,93)$ $\mathrm{nmol} / \mathrm{ml}$. In the study, the mean age of patients is 58,38 years old with duration of disease suffering for more than 10 years. Patient with coronary heart disease and dyslipidemia is included in the study. Investigation of Morsi et al. (2016) also shows an increase in average malondialdehyde measure of 4,5 $(1,5) \mathrm{nmol} / 1$ [24]-[26].

Recent studies demonstrated that glomerular podocyte is a key player in the pathogenesis of diabetic kidney disease. In the past, podocyte injury was thought to be the last process caused by proteinuria in diabetic kidney disease. But biopsy study in human demonstrated that podocyte injury whether functional or structural happens in the earlier phase of diabetic kidney disease. Nephrin is a specific protein in podocytes found in the urine that correlates with podocytes lesion in diabetic nephropathy. The presence of nephrin in the urine happens at the same time with an early injury of the podocyte, even before microalbuminuria exists [27].

Urinary nephrin median is $369,25 \mathrm{ng} / \mathrm{ml}$, with the lowest level of $6 \mathrm{ng} / \mathrm{ml}$ and the highest is $3952 \mathrm{ng} / \mathrm{ml}$. Lioudaki et al. (2015) compared 71 normoalbuminuria patients with type $2 \mathrm{DM}$ and 39 healthy control. The study measures nephrin mRNA level and found a result that nephrin mRNA increased significantly in the normoalbuminuria patients [28].

The study by Jim et al. (2012) to 66 types 2 DM patients and 10 control patients. In this study, nephrinuria is defined as urine-creatinine (UNCR) $\geq 0,1 \mathrm{mg} / \mathrm{g}$. In the control group no nephrinuria is present, and in the normoalbuminuria group, nephrinuria occur in $54 \%$ of all patients with type $2 \mathrm{DM}$, and of all patients with micro and macroalbuminuria, nephrinuria occurs $100 \%$ [29].

Shchukina et al (2015) studied 74 DM samples in Russia and found that nephrinuria is presented in $63 \%$ of normoalbuminuria patients. In a microalbuminuria condition, nephrinuria is found as much as $77 \%$ and $80 \%$ in macroalbuminuria [30]. 


\subsection{Correlation between Serum Glycated Albumin with Urinary Nephrin Level in Type 2 DM patients.}

Spearman test result between serum GA and urinary nephrin in this study reveals a statistically significant result $(\mathrm{p}=0,027)$ with a positive direction and moderate strength correlation (correlation coefficient $\mathrm{r}=0,404$ ). Correlation between serum GA and urinary nephrin shows a positive correlation, means that the higher the serum GA level, the higher the level of urinary nephrin. In this study, we identify that uncontrolled blood glucose shown by GA level will aggravate the diabetic kidney disease, which is reflected by the urinary nephrin [30].

Study of Doublier in 2003 was the first study that correlates glycated albumin and nephrin expression. This study investigates the nephrin distribution in kidney biopsies of 17 patients with DM and nephrotic syndrome, DM microalbuminuria, and 10 control subjects. To the samples, GA was also examined. To determine whether GA influences the nephrin expression, the podocyte was incubated with GA for 48 hours. The study demonstrated a result that GA induced a reduction of nephrin expression on the podocyte surface [31].

A study by Cohen et al. (2013) measured the level of glycated albumin, creatinine, albumin, and nephrin in diabetic murine compared to nondiabetic marines. This study demonstrated a positive linear correlation between GA and urinary nephrin $(\mathrm{p}<0,05$ and $\mathrm{r}=0,58)$. An increase in serum GA concentration is followed by nephrin level increase in diabetic murine. Conversely, if serum GA level is reduced by controlling hyperglycemia, the urinary nephrin also decreased [32].

The correlation strength between serum GA level and urinary nephrin level in this study shows a moderate correlation $(\mathrm{r}=0,404)$. We presume that the presence of a genetic factor affects diabetic kidney disease. Chen G et al. (2013) performed a study in Japan to identify genetic factors predisposing type $2 \mathrm{DM}$ and the gene related to diabetic complications, such as cardiovascular risks and diabetic kidney disease. This study identifies a presence of 17 genes related to diabetes and 4 genes related to diabetic kidney disease. Patients with those genes will promote diabetic kidney disease faster than DM patients without these genes [33].

Bandeira et al. (2013) stated that DM complications could occur as a result of excess oxidative stress and protein glycation. Protein glycation, including albumin, will produce AGEs. Complications will happen if AGEs bounds to its receptor (RAGE). If AGEs doesn't bind to RAGE, then there will be no induction towards cytokines production and oxidative stress. Therefore complications will not appear. Aside from the binding between AGEs and RAGE, DM complications can also happen due to increased intracellular glucose that activates the oxidative stress pathway. In this study, it is not certain whether AGEs and RAGE binding or oxidative stress directly to the cell caused diabetic nephropathy [4].

\subsection{Correlation between Serum Malondialdehyde with Urinary Nephrin Level in Type 2 DM Patients.}

A Spearman test between serum MDA level and urinary nephrin shows a statistically significant result $(\mathrm{p}=0,003)$ with a positive correlation and moderate strength (correlation coefficient $\mathrm{r}=0,528$ ). Correlation between serum MDA and urinary nephrin shows a positive correlation, that means the higher the level of serum MDA, the higher urinary nephrin. This study presented that oxidative stress described by MDA level will aggravate the diabetic kidney disease, which is defined by urinary nephrin [30]. 
We have not found any former research associated with the relation between serum MDA and urinary nephrin in type 2 DM patients. Li et al. (2010) investigated the relation between oxidative stress and nephrin using protein oxidative stress marker, the advanced oxidation protein products (AOPPs). This study reveals an exposure of AOPPs towards podocyte will induce a decrease in nephrin expression [34].

The correlation strength of serum MDA level with urinary nephrin level in this study demonstrated a moderate correlation $(\mathrm{r}=0,528)$. Genetic factor influences the incident of diabetic kidney disease. Gu et al. (2013) proposed relation between genetic polymorphism of ICAM1 (Intercellular Adhesion Molecule 1) with diabetes and diabetic kidney disease. The limitation of this study is the research did not reach those genetic aspects [35].

\section{Conclusion}

Glycated albumin level increased in type 2 diabetes mellitus patients. Serum malondialdehyde increased in patients with type 2 diabetes mellitus. All of the type 2 diabetes mellitus patients had a positive urinary nephrin. There is a positive correlation with a moderate strength between serum glycated albumin level and urinary nephrin level in type 2 diabetes mellitus patients. There is a positive correlation with a moderate strength between serum malondialdehyde level and urinary nephrin level in type 2 diabetes mellitus patients.

\section{References}

[1] Guariguata L, Whiting DR, Hambleton I, Beagley J, Linnenkamp U, Shaw JE, et al. Global estimates of diabetes prevalence for 2013 and projections for 2035. IDF Diabetes Atlas. Diabetes Research and Clinical Practice. 2014;103:137-49

[2] Ramachandran A, Snehalatha C, Ma RCW. Diabetes in South-East Asia: An update. Diabetes Research and Clinical Practice. 2014;103:231-7

[3] Mehrotra R, Zadeh KK, Adler S. Assessment of glycemic control in dialysis patients with diabetes; glycosylated hemoglobin or glycated albumin? Clin J Am Soc Nephrol. 2011;6:1520-2

[4] Bandeira SM, Fonseca LJS, Guedes GS, Rabelo LA, Goulart MOF, Vasconcelos SM. Oxidative stress as an underlying contributor in the development of chronic complications in diabetes mellitus. Int J Mol Sci. 2013;14:3265-84

[5] American Diabetes Association. Standards of medical care in diabetes 2010. Diabetes Care. 2010;33:s11-61

[6] Lee SY, Choi ME. Urinary biomarkers for early diabetic nephropathy: beyond albuminuria. Pediatr Nephrol. 2014;10:s00467

[7] Dinu IR, Mota E. Glycated albumin- more than the missing link in the evaluation of diabetes control. Rom J Diabetes Nutr Metab Dis. 2014;21(2):137-50

[8] Peacock TP, Shihabi ZK, Bleyer AJ, Dolbare EL, Byers JR, Knovich MA, et al. Comparison of glycated albumin and hemoglobin Alc levels in diabetic subjects on hemodialysis. Kidney International. 2008;73:1062-1068

[9] Rodriguez DL, Castelao AM, Gorriz JL, Alvaro FD, Gonzalez JFN. Pathophysiological role and therapeutic implications of inflammation in diabetic nephropathy. World $\mathrm{J}$ Diabetes. 2012;3(1):7-18

[10] Small DM, Coombes JS, Bennett N, Johnson DW, Gobe GC. Oxidative stress, anti-oxidant therapies, and chronic kidney disease. Nephrology. 2012;17:311-21 
[11] Weil EJ, Lemley KV, Mason CC, Yee B, Jones LI, Blouch K, et al. Podocyte detachment and reduced glomerular capillary endothelial fenestration promote kidney disease in type 2 diabetic nephropathy. Kidney International. 2012;82:1010-7

[12] Satchell SC. The glomerular endothelium emerges as a key player in diabetic nephropathy. Kidney International. 2012;82:949-51

[13] Furusyo N, Koga T, Ai M, Otokozawa S, Kohzuma T, Ikezaki E, et al. Utility of glycated albumin for the diagnosis of diabetes mellitus in Japanese population study : results from the Kyushu and Okinawa population study (KOPS). Diabetologia. 2011;54:3028-36

[14] Hilawe EH, Yatsuya H, Aoyama A. Differences by sex in the prevalence of diabetes mellitus, impaired fasting glycaemia and impaired glucose tolerance in Sub-Saharan Africa : a systematic review and meta-analysis. Organ. 2013;91

[15] Lopez J, Bailey R, Rupnow M, Annunziata K. Characterization of type 2 diabetes mellitus burden by age and ethnic groups based on a nationwide survey. Clinical Therapeutics. 2014;36(4):494-506

[16] Solini A, Penno G, Bonora E, Fondelli C, Orsi E, Trevisan R, et al. Age, renal dysfunction, cardiovascular disease, and antihyperglycemic treatment in type 2 diabetes mellitus : findings from the renal insufficiency and cardiovascular events. J Am Geriatr Soc. 2013;61:1253-61

[17] Petrica L, Vlad A, Gluhovschi G, Gadalean F, Dumitrascu V, Gluhovschi C, et al. Proximal tubule dysfunction is associated with podocyte damage biomarkers nephrin and vascular endothelial growth factor in type 2 diabetes mellitus patients. Plos One. 2014;9(11):e112538

[18] Wang N, Xu Z, Han P, Li T. Glycated albumin and ratio of glycated albumin to hemoglobin are good indicators of diabetic nephropathy in type 2 diabetes mellitus. Diabetes/ Metabolism Research and Reviews. 2016;32

[19] Xu Y, Wang L, He J, Bi Y, Li M, Wang T et al. Prevalence and control of diabetes in chinese adults. JAMA. 2013;310(9):948-59

[20] Flegal KM, Caroll MD, Kit BK, Ogden CL. Prevalence of obesity and trends in the distribution of body mass index among US adults. JAMA. 2012;307(5):491-7

[21] Kohzuma T, Yamamoto T, Uematsu Y, Shihabi ZK, Freedman BI. Basic performance of an enzymatic method for glycated albumin and reference range determination. Journal of Diabetes Science and Technology. 2011;5(6):1455-62

[22] Hsu P, Ai M, Kanda R, Chun N, Chen H, Chen W, et al. A comparison of glycated albumin and glycosylated hemoglobin for the screening of diabetes mellitus in Taiwan. Atherosclerosis. 2015;242(1):327-33

[23] Kumawat M, Sharma TK, Singh I, Singh N, Ghalaut VS, Vardey SK, et al. Antioxidant enzymes and lipid peroxidation in type 2 diabetes mellitus with and without nephropathy. NAJMS. 2013;5(3):213-9

[24] Kurutas EB, Gumusalan Y, Cetinkaya A, Dogan E. Evaluation of method performance for oxidative stress biomarkers in urine and biological variations in urine of patients with type 2 diabetes mellitus and diabetic nephropathy. Biological Procedures Online. 2015;17:1-7

[25] Nakhjavani M, Esteghamati A, Nowroozi S, Asgarani F, Rashidi A, Khalilzadeh O. Type 2 diabetes mellitus duration: an independent predictor of serum malondialdehyde levels. Singapore Med J. 2010;51(7):582

[26] Morsi HK, Ismail MM, Gaber HAH, Elbasmy AA. Macrophage migration inhibitory factor and malondialdehyde as potential predictors of vascular risk complications in type 2 diabetes mellitus: Cross sectional case control study in Saudi Arabia. Hindawi. 2016

[27] Bandiara R, Soelaeman MR. Podocyte and Diabetic Kidney Disease. JKM. 2011;11(1):80-91

[28] Lioudaki E, Stylianou KG, Petrakis I, Kokologiannakis G, Passam A, Mikhailidis DP, et al. Increased urinary excretion of podocyte markers in normoalbuminuric patients with diabetes. Nephron. 2015;131: 34-42

[29] Jim B, Ghanta M, Qipo A. Dysregulated nephrin in diabetic nephropathy of type 2 diabetes : A cross sectional study. Plos One. 2012;7:e36041 
[30] Shchukina AA, Bobkova IN, Shestakova MV, Vikulova OK, Zuraeva ZT, Mikhaleva OV. Urinary excretion of markers for podocyte injury in patients with diabetes mellitus. Europe PMC. 2015;87(10):62-6

[31] Doublier S, Salvidio G, Lupia E, Ruotsalainen V, Verzola D, Deferrari G, et al. Nephrin expression is reduced in human diabetic nephropathy. Evidence for a distinct role for glycated albumin and angiotensin II. Diabetes. 2003;52:1023-30

[32] Cohen MP, Shearman CW. Inhibiting Amadori-modified albumin formation improves biomarkers of podocyte damage in diabetic rats. Physiol Rep. 2013;1:1-10

[33] Chen G, Xu Y, Lin Y, Lai X, Yao J, Huang B et al. Association study of genetic variant of 17 diabetes-related genes/ loci and cardiovascular risk and diabetic nephropathy in the Chinese She population. Journal of Diabetes. 2013;5(2):136-45

[34] Li Y, Min L, Qiugen Z, Di X, Aiju L, Xun Z, et al. Advanced oxidation protein products decrease expression of nephrin and podocin in podocytes via ROS-dependent activation of p38 MAPK. Sci China Life Sci. 2010;53:68-77

[35] Gu HF, Ma J, Gu KT, Brismar K. Association of intercellular adhesion molecule 1 (ICAM1) with diabetes and diabetic nephropathy. Frontiers in Endocrinology. 2013;3:43-9 